\title{
WHAT CAN THE RELATION BETWEEN MUSIC AND SPEECH SHOW ABOUT THE BRAIN? A REFLECTION THROUGH PATEL'S "MUSIC, LANGUAGE AND THE BRAIN"
}

O que a relação entre música e fala pode nos mostrar sobre o cérebro? Uma reflexão através da obra "A música, a linguagem e o cérebro”, de Patel

Adriano Bueno Kurle *

\begin{abstract}
In this paper I will try to articulate the relation between speech and music in the mind and brain, using the book Music, Language and the Brain by Aniruddh Patel as reference. This piece of work consists of an analysis comparing music and speech in both functions of the brain and cognitive behavior. Patel defends a thesis against the domain-specific theory, and tries to show that it is possible as well as reasonable, using empirical data to show that music and speech have some common ground in the perceiving process. Then it shall be presented three other sources in philosophy, so that we can have other tools to philosophically reason about this matter. I shall briefly present two other perspectives in philosophy: Humean empiricism and Kantian compatibilism. Thus, to contrast with Patel, I shall present Prinz's empiricist theory, which defends the specific-modality of the senses and perceptions in brain.
\end{abstract}

Keywords: Music, Language, Neuroscience, Philosophy, Patel.
Resumo: Neste artigo buscarei articular a relação entre fala e música na mente e no cérebro, usando para este fim o livro Music, Language and the Brain, de Aniruddh Patel. Este livro consiste em uma análise comparativa entre música e fala nas funções cerebrais e no comportamento cognitivo. Patel defende uma tese contra a teoria de domínio específico, e tenta mostrar que é possível e coerente com os dados empíricos que música e fala tenham alguma origem comum no processo perceptivo. Depois apresentarei três outras fontes na filosofia para que nós possamos ter outras ferramentas para pensar filosoficamente esta questão. Eu irei brevemente apresentar duas outras perspectivas em filosofia, a saber, o empirismo humeano e o compatibilismo kantiano. Então, para fazer um contraste com Patel, eu apresentarei a teoria empirista de Prinz, que defende a modalidade específica dos sentidos e percepções no cérebro.

Palavras-chave: Música, Linguagem, Neurociência, Filosofia, Patel.

\footnotetext{
* Doctoral student at PUCRS, Graduate program in Philosophy. E-mail: adrianobk@gmail.com
}

\begin{tabular}{|c|c|l|l|l|l|}
\hline intuitio & $\begin{array}{c}\text { ISSN } \\
1983-4012\end{array}$ & Porto Alegre & Vol.8 $-\mathrm{N}^{\circ} .1$ & $\begin{array}{c}\text { Junho } \\
2015\end{array}$ & p.228-245 \\
\hline
\end{tabular}


What can the relation between music and speech show about the brain? A reflection through Patel's "Music, Language and the Brain"

\title{
Introduction
}

In this paper I will try to articulate the relation between speech and music in the mind and brain, using the book Music, Language and the Brain by Aniruddh Patel as reference. This piece of work consists of an analysis comparing music and speech in both functions of the brain and cognitive behavior. Patel defends a thesis against the domain-specific theory, and tries to show that it is possible as well as reasonable, using empirical data to show that music and speech have some common ground in the perceiving process. Then it shall be presented three other sources in philosophy, so that we can have other tools to philosophically reason about this matter. I shall briefly present two other perspectives in philosophy: Humean empiricism and Kantian compatibilism. Thus, to contrast with Patel, I shall present Prinz's empiricist theory, which defends the specific-modality of the senses and perceptions in brain. It is important to contrast these two points of view, because Patel's thesis goes against Prinz's thesis.

Patel's issue is about the common sources of music and speech (which he miscalls it as "language" even though he only deals about speech) in the brain. Based on two different kinds of cognitive problems namely aphasia and amusia, it is commonly accepted that both speech and music are controlled by different parts of the brain. If this is correct, we then have different sources in brain for music and speech. That is the thesis that Patel intends to question. Even if we have elements in speech and music that are apart in the brain, we can still have some common source for both as they work with the same physical phenomenon: the sound.

The thesis that Patel wants to support is that we have a common source between music and speech in the production process and learning of the categories. He positions himself against the idea that speech and music are handled by two different sides and different sections of the brain. Despite the fact that the categorization in these two areas do not overlap, Patel defends that the common process occurs before the level of categorization, that it occurs in the level of sound processing.

Music and language (which is taken here equally as "speech") have the common feature of being a systematic use of sound. In Patel's words:

\begin{abstract}
Although within our own minds two systems that perform remarkably similar interpretive feats are found, converting complex acoustic sequences into perceptually discrete elements (such as words or chords) organized into hierarchical structures that convey rich meanings. This provides a special opportunity for cognitive science. Specifically, exploring both the similarities and the differences between music and language can deepen our understanding of the mechanisms that underlie our species' uniquely powerful communicative abilities ${ }^{1}$.
\end{abstract}

\footnotetext{
${ }^{1}$ PATEL, Aniruddh D. Music, Language, and the Brain. OXFORD: Oxford University Press, 2008, p. 03.
}

\begin{tabular}{|c|c|c|c|c|c|}
\hline intuitio & $\begin{array}{c}\text { ISSN } \\
1983-4012\end{array}$ & Porto Alegre & Vol.8 $-\mathrm{N}^{\mathrm{o}} .1$ & $\begin{array}{c}\text { Junho } \\
2015\end{array}$ & p.228-245 \\
\hline
\end{tabular}


What can the relation between music and speech show about the brain? A reflection through Patel's "Music, Language and the Brain"

Therefore, we have different processes in a higher level, but the basic process (at the reception of acoustic signals) is processed in a common level between speech and music. Because we have different syntaxes between these areas (and empirical evidence over different areas for speech and music in the brain), we have a level in which these elements are processed by different neural networks. Therefore, in a higher level, music and speech are different, but (perhaps) they have a common processor.

The main thesis of Patel is called "Shared Sound Category Learning Mechanism Hypothesis" (SSCLMH). To investigate whether this theory is plausible or not, we must consider scientific empirical experiences and reflect on how they are able to support or refute this thesis. Patel brings some cases to us, and he tries to argue in favor of his thesis. The aim of Patel's book in his own words:

This book promotes the alternative perspective [to the 'dissociation thesis'], which emphasizes commonalities over differences. This perspective claims that these two domains, although having specialized representations (such as pitch intervals in music, and nouns and verbs in language), share a number of basic processing mechanisms, and that the comparative study of music and language provides a powerful way to explore these mechanisms. These mechanisms include the ability to form learned sound categories (Chapter 2), to extract statistical regularities from rhythmic and melodic sequences (Chapters 3 and 4), to integrate incoming elements (such as words and musical tones) into syntactic structures (Chapter 5), and to extract nuanced emotional meanings from acoustic signals (Chapter 6). The evidence supporting this perspective comes from diverse strands of research within cognitive science and neuroscience, strands that heretofore have not been unified in a common framework. The final chapter of the book (Chapter 7) takes an evolutionary perspective, and uses musiclanguage comparisons to address the persistent question of whether music is an evolutionary adaptation ${ }^{2}$.

In sum: "The basic motivation is a cognitive one: To what extent does the making and perceiving of instrumental music draw on cognitive and neural mechanisms used in our everyday communication system?",

\section{Cognitive Elements In Music And Speech}

Patel brings us a lot of information through cognitive psychology and neuroscience, trying to show evidences in favor and against the dominant hypothesis in some issues. He divides his book into six areas there are common in both speech and music, and in each area he tries to either relate or separate music and speech. He brings up then pitch and timbre, rhythm, melody, syntax, meaning and evolution, each one being an important element in music and speech. I hereby choose some of the passages and information which I think are most relevant to the purpose of this paper.

\footnotetext{
${ }^{2}$ PATEL, Aniruddh D. Music, Language, and the Brain. OXFORD: Oxford University Press, 2008, p. 04.

${ }^{3}$ PATEL, Aniruddh D. Music, Language, and the Brain. OXFORD: Oxford University Press, 2008, p. 04-05.
}

\begin{tabular}{|c|c|l|l|l|l|}
\hline intuitio & $\begin{array}{c}\text { ISSN } \\
1983-4012\end{array}$ & Porto Alegre & Vol.8 $-\mathrm{N}^{\mathrm{o}} .1$ & $\begin{array}{c}\text { Junho } \\
2015\end{array}$ & p.228-245 \\
\hline
\end{tabular}


What can the relation between music and speech show about the brain? A reflection through Patel's "Music, Language and the Brain"

Patel starts up trying to make the point that, despite the end product of speech and music being different (that is, pitch, chords vs. phonemes, words), the processes that create sound categories have an important degree of overlap. We have a mechanism that creates categories that intervene in our perception, categorizing what we hear into the categories that we learn. Music and speech become two different systems, and are perceived as different elements of different systems. Despite that, speech and music have the common source of acoustic signs, the sonic stimulation, so we have to think why the same thing (that is, sound) becomes element of two different systems, and that despite music and speech being categorized in different systems, they must have something in common in the level of processing: "In fact, there is growing evidence that speech and music share mechanisms for sound category learning, even though the two domains build their primary sound categories from different features of sound ${ }^{4}$." For that, Patel makes the distinction of levels between products and processes: "The implication of this work is that although the end products of sound category learning in music and speech are quite different (e.g., mental representations of pitch intervals vs. consonants), the processes that create sound categories have an important degree of overlap ${ }^{5}$."

The pitch in music is a privileged element: The cross cultural research on music shows that we have few universals in music. Nevertheless there are, hence, some basic elements and characteristics to make music, and other elements that - despite not being a condition to music - tend to appear in almost every culture, having some variations and exceptions. Thus, perhaps these elements can be generalized and called quasi universals.

One general characteristic of music is the centrality of pitch variation, this element becoming frequently systematized in diverse musical cultures. On the other hand, timbre is central for speech, while pitch has a second role. We can think that music could be based in systematized variation of other elements, such as intensity and timbre (we already have a systematization of rhythm in music). Despite the importance of timbre and intensity for music, unlike pitch these elements are not generally rigidly determined, being usually secondary. According to Schoenberg

If it is possible to make compositional structures from sounds which differ according to pitch, structures which we call melodies [...] then it must also be possible to create such sequences from [...] timbre. Such sequences would work with inherent logic; equivalent to the kind of logic which is effective in the melodies based on pitch [...] All of this may seem like some fantasy of the future, it probably is. Yet I am firmly convinced that it can be done ${ }^{6}$.

\footnotetext{
${ }^{4}$ PATEL, Aniruddh D. Music, Language, and the Brain. OXFORD: Oxford University Press, 2008, p. 10.

${ }^{5}$ PATEL, Aniruddh D. Music, Language, and the Brain. OXFORD: Oxford University Press, 2008, p. 10.

${ }^{6}$ SCHOENBERG apud PATEL, Aniruddh D. Music, Language, and the Brain. OXFORD: Oxford University Press, 2008 , p.34.
}

\begin{tabular}{|c|c|l|l|l|l|}
\hline intuitio & $\begin{array}{c}\text { ISSN } \\
1983-4012\end{array}$ & Porto Alegre & Vol.8 $-\mathrm{N}^{\mathrm{o}} .1$ & $\begin{array}{c}\text { Junho } \\
2015\end{array}$ & p.228-245 \\
\hline
\end{tabular}


What can the relation between music and speech show about the brain? A reflection through Patel's "Music, Language and the Brain"

Unlike music, speech has timbre as its main element. In some melodic or pitch languages (as Chinese and African languages) pitch is also important and can change the meaning of words, but the difference in articulation (variation of attack, sustain and decay in time) tends to be central in speech.

Thus, speech is fundamentally a system of organized timbral contrasts. (One might argue that durational patterning is also fundamental to speech, but without timbral contrasts there would be no basis for defining distinct phonemes or syllables, and hence no basis for making durational contrasts.) The human voice is the supreme instrument of timbral contrast. A survey on languages reveals that the human voice is capable of producing timbres corresponding to 800 distinct phonemes, and this represents only phonemes known from extant languages. Of course, no single speaker or language uses this many contrasts: Phoneme inventories range in size from 11 (5 vowels and 6 consonants in Rotokas, a language of Papua New Guinea) to 156 (28 vowels and 128 consonants in !Xóõ, a Khoisan language from South Africa), with the average inventory size being 27 phonemes ${ }^{7}$.

One possible reason for pitch to be so important to music is that its perception is multidimensional. Thanks to its multidimensionality, the pitch perception has both horizontal and vertical relations, generating a spiral that makes it possible to relate similarity between different frequencies, which is what enables us to limit the number of categories that we use for pitch categorization. This relation can be seen in the following graphic:



Figure 1 - The Pitch Helix. Extracted from PATEL, Aniruddh D. Music, Language and the Brain. OXFORD: Oxford University Press, 2008, p. 14.

${ }^{7}$ PATEL, Aniruddh D. Music, Language, and the Brain. OXFORD: Oxford University Press, 2008, p. 51.

\begin{tabular}{|c|c|l|l|l|l|}
\hline intuitio & $\begin{array}{c}\text { ISSN } \\
1983-4012\end{array}$ & Porto Alegre & Vol.8 $-\mathrm{N}^{\circ} .1$ & $\begin{array}{c}\text { Junho } \\
2015\end{array}$ & p.228-245 \\
\hline
\end{tabular}


What can the relation between music and speech show about the brain? A reflection through Patel's "Music, Language and the Brain"

Even though we have no universal rules for pitch organization in music, there are some limitations that determine how we will organize it. Since in a system of communication we must have a clear reference of the shared elements that compose our framework, we must limit the number of its element to a number that is functional as well as shareable. Because the perception is wide and full of spectra and subtleties, for us to have a common understanding and determination, we must categorize a band of the spectrum in one category. Or yet (as it happens in music), we must systematize the relations of spectra, taking some exact spectra in one concept (as a musical note, for example, "Mi"), and exclude the others.

This shows limitation in our processing and recognition. In western music we organize the pitch in 12 notes, and these notes are organized in between a relation of identity (that is, an octave). We take a relation of identity based on our perception of similarity or dissimilarity, and in music this relation is called consonance or dissonance. We could organize that in other ways (as other cultures do), and some intervals seem to be more common in a great variety of cultures (as octave and fifth) than others. Therefore, there is also the way we relate these elements, that is, the syntax.

In this sense, we can see that both in music and in speech we have some sort of delimitation of the acoustic signs as well as its subsumption to categories. Just as in western music we take the notes " $\mathrm{C}, \mathrm{CH}$, D, D\#, E, F" etc, as elementary categories of melodies and chords, in speech we take phonemes as elementary categories to speak. And we also have the relation between these elements that form melodies and chords (in music) and words and phrases (in speech). Both in music and speech there are phrases, and here we have syntax. Therefore, even if they work with different elements of sound, they both have rules of organization for these elements. The musical and speech syntax are obviously different, but we can think whether they have a logical determination in common. Based on that, we could raise the question: does the brain have a common source for logic and syntax or are our perception systems different, and therefore generate different syntaxes?

Hence, one important question is that despite the acoustic sign, in physical terms, is the same for both music and speech, these two work differently and are also processed by different areas of the brain. If we fancy a deeper look by now, we can see that music generally (but not always) systematizes pitch and rhythm. Speech systematizes timbre. One important difference comes clear, and a difference that seems almost - if not totally - universal. Patel shows us evidences for the separation of the two systems in the brain:

There are good reasons to believe that the brain treats spoken and musical sound systems differently. First, focal cortical damage can lead to dramatic dissociations whereby the ability to interpret speech is profoundly impaired, even with the perception of musical sounds being intact, or vice versa. Second, there is great evidence from neuropsychology and neuroimaging that the two cerebral hemispheres have different biases in sound processing. Many musical pitch perception tasks show a greater dependence on right hemisphere circuits,

\begin{tabular}{|c|c|c|c|c|c|}
\hline intuitio & $\begin{array}{c}\text { ISSN } \\
1983-4012\end{array}$ & Porto Alegre & Vol.8 $-\mathrm{N}^{\circ} .1$ & $\begin{array}{c}\text { Junho } \\
2015\end{array}$ & p.228-245 \\
\hline
\end{tabular}


What can the relation between music and speech show about the brain? A reflection through Patel's "Music, Language and the Brain"

whereas many linguistic phonemic tasks show a greater reliance on the left hemisphere ${ }^{8}$.

And yet

It is well known that tasks that focus participants' attention on phonemone perception are associated with greater left-hemisphere activity in neuroimaging studies, often involving a network that spans left superior temporal auditory temporal cortex and left inferior frontal cortex. In contrast, many tasks involving musical pitch perception show a right hemisphere bias. Zatorre et al. (2002) suggest that this difference between speech and music is due to complementary anatomical and functional specializations of the two auditory cortices for processing the temporal versus spectral structure of sound. According to this view, perception of the rapid but spectrally coarse timbral contrasts of speech relies more on left hemisphere circuits, whereas analysis of slower but more spectrally refined pitch contrasts of music relies more on right hemisphere circuits ${ }^{9}$.

If music and speech work with different elements of sound, then it seems more natural to think that this physical sign can generate different systems of reference for the organization of sound. Because we separate this two systems that we can think of both differently, and it is due to this separation that we immediately interpret a sonic event as totally different - if it is categorized as speech or music. Going against this point of view, and nevertheless considering the empirical evidences, Patel raises his own hypothesis:

Indeed, the fact that the mind has found two entirely different ways of building organized sound category systems suggests that sound category learning is a fundamental aspect of human cognition. Thus a natural focus for comparative research on musical and linguistic sound systems is on the mechanisms that create and maintain learned sound categories. To what extent are these mechanisms shared between domains? One possibility is that these mechanisms have little in common. Indeed, evidence for cognitive and neural dissociations between musical and linguistic sound systems would seem to indicate that this is the case. Another possibility is that music and language share mechanisms for sound category learning to an important degree. One might call this 'Shared Sound Category Learning Mechanism Hypothesis (SSCLMH)'. One implication of this hypothesis is that a clear conceptual distinction must be made between the end products of development, which may be specific, and developmental domain processes, which may be domain general ${ }^{10}$.

About this matter, we can think of the plasticity of the brain as something that creates links and networks between neurons depending on the activity and reinforcement that we give to our brain. Then, in music we know that you do not need to be a musician to have some basic comprehension of the music of your culture. But also you can't be a musician and recognize intervals, scales, chords and keys (or

\footnotetext{
${ }^{8}$ PATEL, Aniruddh D. Music, Language, and the Brain. OXFORD: Oxford University Press, 2008, p. 72.

${ }^{9}$ PATEL, Aniruddh D. Music, Language, and the Brain. OXFORD: Oxford University Press, 2008, p. 74.

${ }^{10}$ PATEL, Aniruddh D. Music, Language, and the Brain. OXFORD: Oxford University Press, 2008, p. 72.
}

\begin{tabular}{|c|c|c|c|c|c|}
\hline intuitio & $\begin{array}{c}\text { ISSN } \\
1983-4012\end{array}$ & Porto Alegre & Vol.8 $-\mathrm{N}^{\circ} .1$ & $\begin{array}{c}\text { Junho } \\
2015\end{array}$ & p.228-245 \\
\hline
\end{tabular}


What can the relation between music and speech show about the brain? A reflection through Patel's "Music, Language and the Brain"

anything else that can be a structural element of some musical culture) without training. And we also know that our learning in some aspects is easier if we begin in the childhood - while others you might have to wait till adolescence or adulthood. However it is known that, once you are habituated to one musical system (take here, for example, tonal western music) it will be harder to learn another musical system (for example, the Indian music), because your brain is already adapted to one type of network and behavior (the western music), and to learn Indian music you will have to deconstruct some habits and adapt yourself to another kind of reference. As Patel says:

Even without explicit instruction, most infants develop into adults who are proficient in their native language and who enjoy the music of their culture. These traits come at a price, though: skill in one language can result in difficulty for hearing or producing certain sound distinctions in another and a music lover from one culture may find music of another culture out of tune and annoying! Why is this so? The simple answer is that our native sound system leaves an imprint in our minds. That is, learning a sound system leads to a mental framework of sound categories for our native language or music. This framework helps us extract distinctive units from physical signals rich in acoustic variation. While such frameworks are highly adaptive in our native sonic environment they can also be liabilities when hearing language or music from another culture, because we 'hear with an accent' based on our native sound system ${ }^{11}$.

One common aspect that Patel emphasizes is categorization. Categorization plays an important role both in music and speech, and the categories that the mind develops can have an influence in our perception. Patel thinks that we can find common grounds between music and speech in categories learning and formation. It is advisable to point out two hypotheses: the perceptual magnet effect (PME) and statistical learning ${ }^{12}$. The perceptual magnet effect shows that within categories we have a certain magnetic center or "gravity" that tends to influence the perception in order to adapt the event to an already known category. Statistical learning, on the other hand, "involves tracking patterns in the environment and acquiring implicit knowledge of their statistical properties, without any direct feedback. That is, statistical learning is driven by distributional information in the input rather than by explicit tutoring"13.

When Patel deals with rhythm, he first analyses music, then speech, and takes the role of periodicity as the central issue, as well as the organization of rhythmic events into phrases. He shows that in music we generally have rhythmic periodicity, despite some exceptions. So, through a cross-cultural research, we can see that periodicity is not a universal element of music, but it is (as the fifth and the octave intervals are in pitch) a very common element through cultures. Then, when we do not use periodicity, we use other elements for rhythmic orientation, as body movement or when the singers wait or

\footnotetext{
${ }^{11}$ PATEL, Aniruddh D. Music, Language, and the Brain. OXFORD: Oxford University Press, 2008, p. 09.

${ }^{12}$ Cf. PATEL, Aniruddh D. Music, Language, and the Brain. OXFORD: Oxford University Press, 2008 , p. 79-83.

${ }^{13}$ PATEL, Aniruddh D. Music, Language, and the Brain. OXFORD: Oxford University Press, 2008, p. 79-84.
}

\begin{tabular}{|c|c|c|c|c|c|}
\hline intuitio & $\begin{array}{c}\text { ISSN } \\
1983-4012\end{array}$ & Porto Alegre & Vol.8 $-\mathrm{N}^{\mathrm{o}} .1$ & $\begin{array}{c}\text { Junho } \\
2015\end{array}$ & p.228-245 \\
\hline
\end{tabular}


What can the relation between music and speech show about the brain? A reflection through Patel's "Music, Language and the Brain"

follow instrumental signals for sing phrases, etc. In speech, Patel analyses three main theories for rhythm, and tries to argument against the isochrony and periodicity in speech rhythm.

Patel then argued that, between music and speech, a common characteristic of rhythm is grouping structure, that is, elements are grouped into higher units such as phrases. And the main difference is the use of periodicity, which occurs generally in music but not in speech. In Patel's words, in speech: “A key idea that motivates this research is that linguistic rhythm is the product of a variety of interacting phonological phenomena, and not an organizing principle, unlike the case of music ${ }^{14}$."

Recent researches deny the thesis that humans have universal laws for rhythm perception. It seems that what we have is cultural determination of perception production in different languages and cultures. This can leave us to think (and this is my speculation) that, despite not having unilateral characteristics that are universal and present in all cultures, we could still have rules of process and determination of perception. These rules can be adaptive to the environment, and not unilateral rules, but relational elements that can determine perception in diverse ways.

Patel's position can be summed up in this passage: "Taking a step back, our results show that perception of rhythmic grouping, long thought to follow universal principles, actually vary according to culture ${ }^{15}$."

Patel defines melody as "a constructive process by which the mind converts a sequence of tones into a network of meaningful relationships ${ }^{16}$ ". In chapter 4 of the book, Patel compares musical melody to speech melody as linguistic intonation, examining that element of melodic speech which carries structural information. Music melody has structural relations that speech does not have, such as relation between notes, scales, chords and tonal center. Because music has it and speech does not, music melody generates more rich meta-relations ${ }^{17}$. In speech there are no stable interval structures.

Patel deals with melody processing and tries to provide evidences for overlapping between music and speech in cognitive and neural machinery. He also deals with the apparent dissociation between music and speech melody in musically tone-deaf individuals ${ }^{18}$. He starts trying to show cross-cultural regularities between music and speech, which can have a common source. The first one is that we have some tendency to deal with small variation of pitch, or with small intervals, between successive pitches. The causes could be the conjunction of two elements: perceptual limitations (because large pitch movements could split the

\footnotetext{
${ }^{14}$ PATEL, Aniruddh D. Music, Language, and the Brain. OXFORD: Oxford University Press, 2008, p. 176-177.

${ }^{15}$ PATEL, Aniruddh D. Music, Language, and the Brain. OXFORD: Oxford University Press, 2008, p. 173.

${ }^{16}$ PATEL, Aniruddh D. Music, Language, and the Brain. OXFORD: Oxford University Press, 2008, p. 182.

${ }^{17}$ Cf. PATEL, Aniruddh D. Music, Language, and the Brain. OXFORD: Oxford University Press, 2008, p. 183; 205.

${ }^{18}$ Cf. PATEL, Aniruddh D. Music, Language, and the Brain. OXFORD: Oxford University Press, 2008, p. 218.
}

\begin{tabular}{|c|c|c|c|c|c|}
\hline intuitio & $\begin{array}{c}\text { ISSN } \\
1983-4012\end{array}$ & Porto Alegre & Vol. $-\mathrm{N}^{\circ} .1$ & $\begin{array}{c}\text { Junho } \\
2015\end{array}$ & p.228-245 \\
\hline
\end{tabular}


What can the relation between music and speech show about the brain? A reflection through Patel's "Music, Language and the Brain"

melody into separate perceptual streams, destroying its unity) and motor ones (singing, speaking or playing an instrument) ${ }^{19}$.

But what can we say by "small" here? Music deals generally with intervals between half and one and a half tones on the notes of the scales. Speech rarely makes variations that great. The case that we use the minor intervals to make melodic progressions only shows that is better to our understanding to follow the elements of melodic variation if they are close, but it does not show that the way we do this is the same in music as in speech. Maybe this occurs because our comprehension of pitch variation in music already presupposes the structural and syntactical ground that music occurs, and thus shows that closer elements are easier to follow.

The other attempt to approximate music and speech in neural processing goes through the analysis of acquired amusia: "Acquired amusia refers to deficits in musical perception and/ or production abilities following brain damage that are not simple due to hearing loss or some other peripheral auditory disorder ${ }^{20}$." Quoting an experiment of Patel, Peretz et al. he then tries to ground his thesis on empirical ground:

The rationale behind the study was that if the amusics' perceptual deficits were confined to music, they should perform well on discriminating the sentences despite having difficulty with the tone sequences; in other words, dissociation between speech and nonlinguistic tone sequence processing should be observed. On the other hand, if intonation and tone-sequence processing overlap in the brain, then similar performance on the two types of sequences should be found. The results of the study supported the second conclusion ${ }^{21}$.

Later he deals with musically tone-deaf individuals, who do not have any psychological problems with speech or other cognitive abilities, but cannot recognize pitch movement in music, notes out of key and are totally unable to deal with and recognize melodies. A study by Ayotte shows counter evidence against Patel's thesis, because it finds dissociation in tone-deaf individuals' performance on the melodic recognition between sentences and non-linguistically analogs $\mathrm{s}^{22}$. This can be taken in favor for modularity thesis and against Patel's thesis. So he tries to articulate a hypothesis to answer this problem, based on idea that melodic contour perception in speech and music rely on common neural circuitry. He calls this thesis the "melodic contour deafness hypothesis".

The idea of this thesis is that these individuals with musical tone deafness have equivalent problems with direction of pitch change, because intonation perception can deal with this problem in speech - but not in music, since it has more complex direction changes. That is, this individuals can

${ }^{19}$ Cf. PATEL, Aniruddh D. Music, Language, and the Brain. OXFORD: Oxford University Press, 2008, p. 218-219.

${ }^{20}$ PATEL, Aniruddh D. Music, Language, and the Brain. OXFORD: Oxford University Press, 2008, p. 226.

${ }^{21}$ PATEL, Aniruddh D. Music, Language, and the Brain. OXFORD: Oxford University Press, 2008, p. 227-228.

${ }^{22}$ Cf. PATEL, Aniruddh D. Music, Language, and the Brain. OXFORD: Oxford University Press, 2008, p. 230.

\begin{tabular}{|c|c|c|c|c|c|}
\hline intuitio & $\begin{array}{c}\text { ISSN } \\
1983-4012\end{array}$ & Porto Alegre & Vol. $-\mathrm{N}^{\circ} .1$ & $\begin{array}{c}\text { Junho } \\
2015\end{array}$ & p.228-245 \\
\hline
\end{tabular}


What can the relation between music and speech show about the brain? A reflection through Patel's "Music, Language and the Brain"

perceive that pitch changes, but they do not perceive if they go up or down. Therefore, they cannot understand music, but they are well able to understand the accents of speech, for in speech the direction perception is not so important to the meaning. Showing some evidences to its thesis, Patel concludes:

This suggests an independent pitch-direction deficit. There are reasons to believe that such deficit could arise from abnormalities in right auditory cortex. Research on patients with surgical excisions of temporal lobe regions has revealed that individuals with excisions of right secondary auditory cortex (lateral Heschl's gyrus) have pronounced deficits in judging pitch direction, even though their thresholds for simple pitch change detection are normal. In contrast, patients with comparable excisions of left auditory cortex show no such direction deficits (Johnsrude et al., 2000). Evidence supporting a link between pitch-direction detection and melodic contour perception is the fact that both are disrupted by lesions to right auditory cortex (Johnsrude et aI., 2000; Liegeois-Chauvel et aI., $1998)^{23}$.

He then tries to show where this problem can be found, and he thinks that in the two cases of deafness (previously presented) the problem might be in short-term memory for pitch, which can engage modular problems but finding a common ground in the processing of acoustic sign between music and speech. As he concludes, "In other words, a behavioral dissociation is not necessarily the same as a neural dissociation: A non-domain specific deficit can give rise to domain-specific problems because of the different demands that each domain places in the ability in question" ${ }^{24}$.

The last element (and I find it the most interesting one for our philosophical issue - which will be developed later) is syntax. Even though in his book Patel still presents meaning and evolution relations between music and speech (chapter 6 and 7), I think meaning is a hard thing to define in music, and I do not believe Patel solves this problem.

Given that we have syntax on both speech and music, the question that arises here is how can we explain that we have two types of syntax in two different brain systems? What Patel decides to go against here is the domain-specific thesis (which is later worked based on Jesse Prinz), trying to find common sources for both music and speech syntax. He believes that we have evidence for significant neural overlap in syntax between these two domains ${ }^{25}$.

A comparison between music and speech shows that both have some formal and logical similarities, such as multiple levels of combinatorial organization, hierarchical structuring between elements in sequence, grammatical categories that can be filled by different physical entities, relationship structure versus elaboration, and context dependent grammatical functions involving interdependent relations between elements. For Patel it can suggest "basic principles of syntactic organization employed

\footnotetext{
${ }^{23}$ PATEL, Aniruddh D. Music, Language, and the Brain. OXFORD: Oxford University Press, 2008, p. 236.

${ }^{24}$ PATEL, Aniruddh D. Music, Language, and the Brain. OXFORD: Oxford University Press, 2008, p. 238.

${ }^{25}$ Cf. PATEL, Aniruddh D. Music, Language, and the Brain. OXFORD: Oxford University Press, 2008, p. 241; 267.
}

\begin{tabular}{|c|c|l|l|l|l|}
\hline intuitio & $\begin{array}{c}\text { ISSN } \\
1983-4012\end{array}$ & Porto Alegre & Vol.8 $-\mathrm{N}^{\circ} .1$ & $\begin{array}{c}\text { Junho } \\
2015\end{array}$ & p.228-245 \\
\hline
\end{tabular}


What can the relation between music and speech show about the brain? A reflection through Patel's "Music, Language and the Brain"

by human mind"26. This thesis Patel calls "Shared Syntactic Integration Resource Hypothesis". Basically, he believes that even the brain having distinct domain-specific syntactic representations (for example, chords vs. words) they share neural resources for activating and integrating these representations ${ }^{27}$.

Patel develops this theory to deal with a paradox generated by evidences for dissociation in cognitive research and evidences for overlap in neuroimaging. For Patel:

These observations suggest that the overlap in linguistic and musical syntax is not in the level of representation. Thus one way to break the paradox outlined above is to propose a conceptual distinction between syntactic representation and syntactic processing. This can be understood as the distinction between longterm structural knowledge in a domain (i.e., in associative networks that store knowledge of words and chords) and operations conducted on that knowledge for the purpose of building coherent percepts. A key idea of this approach is that some of the processes involved in syntactic comprehension rely on brain areas separate from those areas in which syntactic representations reside ${ }^{28}$.

Different from other hypothesis in the area, Patel's thesis does not purpose that a common memory system or symbol manipulation system is shared between the two areas. He tries to find the common ground by comparing cognitive theories of syntactic processes in these two domains. Hence, Patel presents two cognitive syntactic theories for speech: the Dependency Locality Theory (DLT) and Expectancy Theory. The first:

Gibson's dependency locality theory (DLT; Gibson, 1 998, 2000) was developed to account for differences in the perceived complexity of grammatical sentences and for preferences in the interpretation of syntactically ambiguous sentences. DLT posits that linguistic sentence comprehension involves two distinct components, each of which consumes neural resources. One component is structural storage, which involves keeping track of predicted syntactic categories as a sentence is perceived in time (e.g., when a noun is encountered, a verb is predicted in order to form a complete clause). The other component is structural integration, in other words, connecting each incoming word to a prior word on which it depends in the sentence structure. A basic premise of this theory is that the cost of integration is influenced by locality: Cost increases with the distance between the new element and the site of integration. Distance is measured as the number of new 'discourse referents' (nouns and verbs) since the site of integration. Thus DLT uses a linear measure of distance rather than a hierarchical one (e.g., based on counting nodes in a syntactic tree), and thus does not depend on the details of any particular phrase structure theory ${ }^{29}$.

For Patel "The relevant aspect of the theory for the current purpose is the idea that mentally connecting distant elements require more resources ${ }^{30}$,. The Expectancy Theory is associated with how

\footnotetext{
${ }^{26}$ PATEL, Aniruddh D. Music, Language, and the Brain. OXFORD: Oxford University Press, 2008, p. 267.

${ }^{27}$ PATEL, Aniruddh D. Music, Language, and the Brain. OXFORD: Oxford University Press, 2008, p. 268.

${ }^{28}$ PATEL, Aniruddh D. Music, Language, and the Brain. OXFORD: Oxford University Press, 2008, p. 276.

${ }^{29}$ PATEL, Aniruddh D. Music, Language, and the Brain. OXFORD: Oxford University Press, 2008, p. 277.

${ }^{30}$ Cf. PATEL, Aniruddh D. Music, Language, and the Brain. OXFORD: Oxford University Press, 2008, p. 278.
}

\begin{tabular}{|c|c|c|c|c|c|}
\hline intuitio & $\begin{array}{c}\text { ISSN } \\
1983-4012\end{array}$ & Porto Alegre & Vol.8 $-\mathrm{N}^{\circ} .1$ & $\begin{array}{c}\text { Junho } \\
2015\end{array}$ & p.228-245 \\
\hline
\end{tabular}


What can the relation between music and speech show about the brain? A reflection through Patel's "Music, Language and the Brain"

well a word fits a perceiver's syntactic expectations at that point. That is, during sentence comprehension, a perceiver has specific expectations for upcoming syntactic categories of words. "This reflects structural analysis of the sentence currently being considered by the parsing mechanism. When a word is found not to match the most favored analysis, resources must be reallocated in order to change the preferred structural interpretation ${ }^{31}$."Again, the relevant point here is that it posits that difficult syntactic integrations consume processing resources used in building structural representations of sentences.

In music we also have a theory that uses expectancy and a harmonic framework that uses stored information and tries to adapt new information to this framework. So here we also have the use for memory resources and mechanism of integration between the framework (for example, tonal system) and the new information, and that information which is unexpected or distant from the pattern framework uses more resources (Tonal Pitch Space Theory). Patel thinks that

Overlap in the syntactic processing of language and music can thus be conceived of as overlap in the neural areas and operations that provide the resources for difficult syntactic integrations, an idea termed the 'shared syntactic integration resource hypothesis' (SSIRH). According to the SSIRH, the brain networks providing the resources for syntactic integration are 'resource networks' that serve to rapidly and selectively bring low-activation items in 'representation networks' up to the activation threshold needed for integration to take place ${ }^{32}$.

Patel thinks that the suggestion of frontal brain regions being possibly the neural location for these hypothesized overlapping is consistent with empirical research. This thesis predicts that "tasks which combine linguistic and musical syntactic integration will show interference between them both ${ }^{33}$ ". Patel then shows experiments that are motivated by Shared Syntactic Integration Hypothesis, and this can be seen as a good evidential basis for his thesis, despite for a stronger conclusion yet needs further empirical analysis.

\section{Philosophical Issues And Prinz's Domain Specific Theory}

Given the cognitive characteristics that have just been discussed above, we can now speculate through philosophical thesis, and then apply it to the case of brain acoustic perception process - and then, through this later action, evaluate Patel's thesis as well as other possibilities. We hereby aim to present three philosophical theses: Kantian, Humean, and Prinz's thesis. The Kantian shall make us believe that we have central logical rules to determine the different relations of elements, therefore giving us the possibility to have a common source for human mind, despite the cultural conditioning. Hume's and Prinz's theses are empiricist; then, through Hume we have principles for perception relations that are not $a$

${ }^{31}$ Cf. PATEL, Aniruddh D. Music, Language, and the Brain. OXFORD: Oxford University Press, 2008, p. 278-279.

${ }^{32}$ PATEL, Aniruddh D. Music, Language, and the Brain. OXFORD: Oxford University Press, 2008, p. 283.

${ }^{33}$ PATEL, Aniruddh D. Music, Language, and the Brain. OXFORD: Oxford University Press, 2008, p. 285.

\begin{tabular}{|c|c|l|l|l|l|}
\hline intuitio & $\begin{array}{c}\text { ISSN } \\
1983-4012\end{array}$ & Porto Alegre & Vol.8 $-\mathrm{N}^{\circ} .1$ & $\begin{array}{c}\text { Junho } \\
2015\end{array}$ & p.228-245 \\
\hline
\end{tabular}


What can the relation between music and speech show about the brain? A reflection through Patel's "Music, Language and the Brain"

priori (different from Kant) rules for perception production, but rules for relation of ideas. Prinz has a modular empiricist thesis, which says that our brain works with modular processing, having different areas for processing different sense data. Against Prinz's thesis, we can raise a central processing thesis. It is with that position that we will evaluate Patel's thesis.

It is important here to remember that Patel does not elaborate an argumentative or speculative explication of what he thinks the acoustic signal processing is, and how we can relate our music perception to speech perception. What he does is simply to present some scientific support and, in each of the areas (pitch, timbre, rhythm, melody, etc.), to present some short possibilities towards a unified vision and suggestions for new research. So we have a thesis that is not systematically and philosophically developed.

Firstly, the empiricist thesis in one of his classical and best philosophical formulations. In the experience and human understanding analysis, Hume distinguishes between two sources of the understanding operation, what he understands as two forms of perception: the impressions and the thoughts or ideas. These both have its source in experience, but they distinguish by distinct grades of strength and vivacity. The impressions are lively and strong perceptions - being either external (as the external perceptions of objects through the senses) or internal (as feelings and passions) - that are immediate experiences or very close to immediate experiences. On the other side, ideas are weaker perceptions, and refer to experience by an abstract manner, which may be generated by the combination of the impressions, when we reflect about any of the sensations or impressions. Hume believes that by combination we are capable of forming a diversity of ideas, and with this conceive what is beyond our sensations and perception of reality ${ }^{34}$.

The main characteristic of Humean's thought, at this point, is that all our knowledge comes from our senses and the closeness to the pure impressions are the way to truth and best understanding of reality. So, this empiricist thesis says that all our representations and concepts derive from our sensations, and our abstract ideas or concepts are something like weaker sensations of these impressions, combined between them through three essential rules of ideas combinations: resemblance, contiguity and cause-effect. It is through the combinations of these ideas we give rise to more abstract concepts.

It is very important for us to understand Prinz's position, because he is an empiricist in a "Humeanlike" way. Hume's position can be opposed by Kant's position. Unlike the empiricists, a Kantian way of thinking considers two elements: firstly, that our way to describe anything, being either objects of the world or the way our mind functions, already presupposes some a priori elements, that are present in all our perceptions and determines not only the way we relate perceptions, representations and ideas, but

\footnotetext{
${ }^{34}$ Cf. HUME, David. An Enquiry Concerning Human Understanding. Oxford: Oxford University Press, 1999.
}

\begin{tabular}{|c|c|c|c|c|c|}
\hline intuitio & $\begin{array}{c}\text { ISSN } \\
1983-4012\end{array}$ & Porto Alegre & Vol.8 $-\mathrm{N}^{\mathrm{o}} .1$ & $\begin{array}{c}\text { Junho } \\
2015\end{array}$ & p.228-245 \\
\hline
\end{tabular}


What can the relation between music and speech show about the brain? A reflection through Patel's "Music, Language and the Brain"

constitutes and constructs these perceptions, representations and ideas itself. So, to speak about anything in the world or in our mind, we have first to considerate that we must presuppose some constituent elements and the use of concepts. If we must use concepts to speak about things, all our investigation can, and must, also reflect upon the concepts we use and what justification we have to apply these concepts in a certain context. Secondly, Kant believes that we have some universal ground to constitute our experience: our sensibility already has space and time as its ground, and the constitution of our experience also presupposes the application of pure (so, a priori, independent of experience) concepts, that are something as structural components of our understanding, that are in combination applied to sense data to form our conscious experience ${ }^{35}$.

I take here Prinz's position in the book Furnishing the Mind ${ }^{36}$, in which he elaborates an empiricist concept theory. We shall try to focus on the elements that are important to our discussion; hence the specific issue of concepts does not take a central role here.

Prinz defends that all concepts have their origins and relation to perceptions. He develops an idea that each perception has its specific code, and that the elements from diverse perceptions are related between each other through convergence zones in the brain. His position is in favor of the modal specificity of the perceptions, and against both a common code and amodal theory. For Prinz, thought has no common code through which all perceptions are related and organized.

Part of this work involves a redefinition of what perceptual representations are. Defining distinction between what the senses are from the intellect could be one way. Prinz tries to deny the idea that our senses are merely passive. The senses are input systems that answer to the environment. Based on the idea that each sense has its specific modality, senses are defined as systems that answer to particular classes of input. The senses have independence from one another, functioning and answering each one its own way, but it does not imply that they are isolated from each other.

The idea that each sense operates in its own particular way, Prinz takes from Fodor. This idea basically is that

Sensory systems, unlike the intellect, are modular. Modular systems are fast, domain specific, associated with specific neural architectures, and informationally encapsulated. Saying that perceptual systems are informationally encapsulated means that processing in perceptual systems cannot be influenced by information contained in other systems ${ }^{37}$.

\footnotetext{
${ }^{35}$ Cf. KANT, Immanuel. Kritik der reinen Vernunft. Hamburg: Verlag von Felix Meiner, 1956.

${ }^{36}$ PRINZ, Jesse J. Furnishing the Mind: Concepts and their perceptual basis. Cambridge: The MIT Press, 2002.

${ }^{37}$ PRINZ, Jesse J. Furnishing the Mind: Concepts and their perceptual basis. Cambridge: The MIT Press, 2002, p. 116.
}

\begin{tabular}{|c|c|c|c|c|c|}
\hline intuitio & $\begin{array}{c}\text { ISSN } \\
1983-4012\end{array}$ & Porto Alegre & Vol.8 $-\mathrm{N}^{\circ} .1$ & $\begin{array}{c}\text { Junho } \\
2015\end{array}$ & p.228-245 \\
\hline
\end{tabular}


What can the relation between music and speech show about the brain? A reflection through Patel's "Music, Language and the Brain"

This does not imply that they not relate, because this information can be bounded through mapping in convergence zones, not having the implication that this information affects the input in a specific perceptual system. Aside from the concepts that one has (as a band of perceptual representations related to an intentional object) an auditory sign will be picked in a modular auditory system without direct influence in visual system. For Prinz "To say that senses are systems means that they can be divided up internally, in our case, by distinct collections of cooperative neural populations ${ }^{38, "}$.

The relation between specific codes occurs through convergence zones, an idea taken from Damasio:

A convergence zone is a neural record of activity in perceptual areas of the brain (including sensory and emotional centers). When simultaneous activity occurs in perceptual areas during perception, convergence zones are formed. Convergence zones are hierarchically organized. First-order convergence zones store records of co-occurring perceptual features, and higher-order convergence zones store records of lower-order convergence zones. By first binding together features and then binding collections of bound features together, convergence zones can scale up to store records of complex event sequences. Convergence zones are not merely records. They can also be used to 'retroactivate' the perceptual states from which they came. This is essential to the role they play in cognition. For example, we make plans by using convergence zones to retroactivate the perceptual states that would arise if those plans were executed. For convergence zones to be of any use, they must be able to retroactivate modality-specific perceptual states in this way. Thinking works by perceptual reenactment ${ }^{39}$.

Because the perceptions are considered modal-specific, their relations are made through these convergence zones, what seems to require the transposition from one modality to another, for it can be bounded to form a concept of an object.

In relation to this transposition between modalities (intermodality), Prinz argues that because the thought occurs in accordance with its perceptions, and that the perceptions occur in specific-modalities, the transposition between one mode to another does not need a common code, but can occur directly from one mode to another. Now the question is: if this transposition occurs in a way to maintain the unit of the object in its diverse modalities of perception, does not it require rules for the transposition - which therefore does not pertain to any specific modality? That is, even though not having a specific common code, does not the intermodal relation require rules that are reducible neither to one modality, nor to other, but independent rules?

The answer to that question is the supposition that there are cells that operate in two modalities or at least deal with common aspects between the two modalities (for example, space in audition and

\footnotetext{
${ }^{38}$ PRINZ, Jesse J. Furnishing the Mind: Concepts and their perceptual basis. Cambridge: The MIT Press, 2002, p. 116.

${ }^{39}$ PRINZ, Jesse J. Furnishing the Mind: Concepts and their perceptual basis. Cambridge: The MIT Press, 2002, p. 128.
}

\begin{tabular}{|c|c|l|l|l|l|}
\hline intuitio & $\begin{array}{c}\text { ISSN } \\
1983-4012\end{array}$ & Porto Alegre & Vol.8 $-\mathrm{N}^{\circ} .1$ & $\begin{array}{c}\text { Junho } \\
2015\end{array}$ & p.228-245 \\
\hline
\end{tabular}


What can the relation between music and speech show about the brain? A reflection through Patel's "Music, Language and the Brain"

space in vision). The mapping occurs in a direct way, without necessity of transposition for a meta-code or a common code:

Consider how a direct mapping would work. Suppose that two separate modalities contain cells that respond to a common feature of the environment, such as a location in space. To communicate, externally induced activation of space cells in one modality might cause activation of the corresponding space cells in the other modality. With this configuration, there would be cells within each modality that responded to stimulation from that modality, from the other modality, and, maximally, to simultaneous stimulation in the two modalities ${ }^{40}$.

The second strategy is to defend that some cells are bi-modals, and that it functions as bridge cells: "Cells that appear to be amodal might serve as convergence zones ${ }^{41}$ ". But is not it simply the same to say these cells are amodal (that serves to multiples modalities in the senses, as a central code)? Or does that difference only accumulate perceptions over itself, without transposing or transforming the specific content? But how could this accumulation occur (this synthesizing of different modalities in common cells groups) if these cells do not contain either a transposing capacity of the two modalities in a third one or the capacity to join both synthetically?

Prinz answers that convergence zones are cells population that store simultaneous activity in sensorial areas, and serve to reactivate these areas during the cognition. He accepts amodals cells but under the condition that it is understood as being related to the role of storing and relating specific modal cells activity. "If an amodal code exists, it works on credit rather than serving as the primary currency of thought ${ }^{42}$.

\section{Conclusion}

We could think the neuroscientific approach of Patel and Prinz as variations of both Kantian and Humean philosophical positions. Prinz already poses himself as an empiricist, and has principles very similar to Hume's, despite his theory (as a contemporary thesis) being scientifically more sophisticated, and having a much more empirical ground. In another way, Patel's position is not something that we can think as a Kantian position, though he poses himself against the domain-specific thesis of Fodor (whom, by the way, has great influence over Prinz's work). I believe that Kant has something important that is seen in Patel but not in Prinz; that is, the belief that modal systems, as language and musical systems, have

\footnotetext{
${ }^{40}$ PRINZ, Jesse J. Furnishing the Mind: Concepts and their perceptual basis. Cambridge: The MIT Press, 2002, p. 136.

${ }^{41}$ Cf. PRINZ, Jesse J. Furnishing the Mind: Concepts and their perceptual basis. Cambridge: The MIT Press, 2002, p. 137.

${ }^{42}$ PRINZ, Jesse J. Furnishing the Mind: Concepts and their perceptual basis. Cambridge: The MIT Press, 2002, p.136.
}

\begin{tabular}{|c|c|c|c|c|c|}
\hline intuitio & $\begin{array}{c}\text { ISSN } \\
1983-4012\end{array}$ & Porto Alegre & Vol.8 $-\mathrm{N}^{\circ} .1$ & $\begin{array}{c}\text { Junho } \\
2015\end{array}$ & p.228-245 \\
\hline
\end{tabular}


What can the relation between music and speech show about the brain? A reflection through Patel's "Music, Language and the Brain"

some common ground that are processed in a common language - and that influences the input (our perception of the data senses are influenced by our categories and processing capacities).

So, we have in Patel something that is (perhaps in a weaker way) closer to Kant than to Hume. As Kant thinks that we have a common conceptual ground that rules all our perception formation and relation, Patel's way finds some mid-ground between Kant and Hume, because he accepts that we can have two different sites of representation in the systems - nevertheless, he thinks that we can have different areas of processing the sense data that are prior to the specific systems. So, we maybe can think that some modal systems of the brain have common ground in other processing places, and through this, we can think (in a Kantian way, not what Patel thinks) that all our cognitive elements are related between them through some normative conceptual source, that are not exactly some empirical "thing", but presuppositions that we must have to think the elements that we investigate altogether when we do science, in specific, neuroscience.

Looking from another point of view, Hume's principles for relation of ideas can be used as principles that are not domain-specific, but general modes of relation - that is, universal logical modes of relations in mind. So, despite that we have different systems between music and speech, we can maybe have common forms of relations and organization and comparison of phrases and melodic elements in music and phrases and semantic elements in speech - as in both we can analyze through principles as resemblance, contiguity and cause-effect ${ }^{43}$.

\section{Bibliography}

HUME, David. An Enquiry Concerning Human Understanding. Oxford: Oxford University Press, 1999. KANT, Immanuel. Kritik der reinen Vernunft. Hamburg: Verlag von Felix Meiner, 1956. PATEL, Aniruddh D. Music, Language and the Brain. Oxford: Oxford University Press, 2008. PRINZ, Jesse J. Furnishing the Mind: Concepts and their perceptual basis. Cambridge: The MIT Press, 2002.

Recebido em: 17/09/2014

Aprovado para publicação em: 22/11/2014

${ }^{43}$ Cf. PATEL, Aniruddh D. Music, Language, and the Brain. OXFORD: Oxford University Press, 2008, p. 336-340.

\begin{tabular}{|c|c|l|l|l|l|}
\hline intuitio & $\begin{array}{c}\text { ISSN } \\
1983-4012\end{array}$ & Porto Alegre & Vol.8 $-\mathrm{N}^{\circ} .1$ & $\begin{array}{c}\text { Junho } \\
2015\end{array}$ & p.228-245 \\
\hline
\end{tabular}

